\title{
Does the Degree of Acculturation Influence Breastfeeding \\ Intention and Start or the Frequency of Early Weaning? \\ Results of a Prospective Observational Study
}

\author{
Beeinflusst der Akkulturationsgrad Stillabsicht und -beginn \\ oder die Häufigkeit vorzeitigen Abstillens? \\ Ergebnisse aus einer prospektiven Beobachtungsstudie
}

\section{(ㅇ)(1) (우}

Authors

Silke Brenne ${ }^{1,4}$, Jürgen Breckenkamp², Theda Borde ${ }^{3}$, Matthias David ${ }^{4 *}$, Oliver Razum²*

Affiliations

1 Otto-von-Guericke-Universität Magdeburg, Medizinische

Fakultät, Institut für Allgemeinmedizin, Magdeburg, Germany

2 Universität Bielefeld, Fakultät für Gesundheitswissenschaften, AG 3 - Epidemiologie \& International Public Health, Bielefeld, Germany

3 Alice Salomon-Hochschule, Berlin

4 Charité - Universitätsmedizin Berlin, Klinik für Gynäkologie, Campus Virchow-Klinikum, Berlin, Germany

Key words

breastfeeding, breastfeeding behaviour, breastfeeding prevalence, migration, acculturation

Schlüsselwörter

Stillen, Stillverhalten, Stillprävalenz, Migration, Akkulturation

received 26.3.2018

accepted 5.4.2018

Bibliography

DOI https://doi.org/10.1055/a-0601-6873

Geburtsh Frauenheilk 2018; 78: 596-604 @ Georg Thieme

Verlag KG Stuttgart · New York | ISSN 0016-5751

Correspondence

Prof. Dr. med. Matthias David

Charité - Universitätsmedizin Berlin,

Campus Virchow-Klinikum, Klinik für Gynäkologie

Augustenburger Platz 1, 13353 Berlin, Germany

matthias.david@charite.de

$\Theta$

Deutsche Version unter:

https://doi.org/10.1055/a-0601-6873

\section{ABSTRACT}

Objectives Recent breastfeeding studies from immigration countries have found that acculturation factors influence breastfeeding behaviour in women with a migration background. To date, there has been no systematic investigation for Germany. Therefore, we study whether and how the degree of acculturation within a population of migrant women influences the start, time and duration of breastfeeding.

Patient Population and Methodology Pregnant women who were admitted to one of the three participating maternity clinics in Berlin for the birth of their child in the one-year study period were surveyed (including sociodemographic details, data on migration/acculturation). These women were interviewed again two or three days post partum (including start of breastfeeding, planned breastfeeding duration, reasons for not breastfeeding). In a subgroup, a telephone interview took place 6 months post partum about the actual breastfeeding duration, contraceptive behaviour post partum and availing of midwife services following delivery. Breastfeeding behaviour was analysed using multivariate regression models, among other things.

Results The prepartum survey included 7100 women, 6884 women were contacted in the postnatal wards, and the subgroup six months after delivery comprised 605 women. No acculturation-related differences were found in the start of breastfeeding. In the adjusted model, a medium and higher degree of acculturation diminished the chance of planning a long breastfeeding period. More acculturated women show a greater risk of weaning within the first six months than less acculturated women.

Conclusion The degree of acculturation has relevant significance for some aspects of breastfeeding behaviour in women with a migration background. This should be considered both in breastfeeding promotion programmes and in further national breastfeeding studies.

* Shared last authorship 


\section{ZUSAMMENFASSUNG}

Fragestellungen Neuere Stillstudien aus Einwanderungsländern fanden einen Einfluss von Akkulturationsfaktoren auf das Stillverhalten bei Frauen mit Migrationshintergrund (MH). Eine systematische Untersuchung für Deutschland fehlt bisher. Es soll daher untersucht werden, ob und wie der Akkulturationsgrad innerhalb eines Migrantinnenkollektivs Stillbeginn, -zeit und -dauer beeinflusst.

Patientinnenkollektiv und Methodik Es wurden schwangere Frauen befragt, die im 1-jährigen Untersuchungszeitraum in einer der 3 teilnehmenden Berliner Geburtskliniken zur Geburt ihres Kindes aufgenommen wurden (u. a. soziodemografische Angaben, Daten zu Migration/Akkulturation). Diese Frauen wurden nochmals 2 bzw. 3 Tage post partum interviewt (u.a. Stillbeginn, geplante Stilldauer, Gründe für Nichtstillen). Bei einem Teilkollektiv erfolgte 6 Monate post partum ein Telefoninterview zur tatsächlichen Stilldauer, zum Verhütungsverhalten post partum und zur Inanspruchnahme von Hebammenangeboten nach der Entbindung. Das Stillverhalten wurde u.a. anhand multivariater Regressionsmodelle analysiert.

Ergebnisse Das präpartal befragte Kollektiv umfasste 7100 Frauen, auf den Wochenbettstationen konnten insgesamt 6884 Frauen erreicht werden, beim Teilkollektiv 6 Monate nach der Entbindung 605 Frauen. Es zeigten sich keine akkulturationsbedingten Unterschiede beim Stillbeginn. Im adjustierten Modell verringerten ein mittlerer und höherer Akkulturationsgrad die Chance, eine lange Stillzeit zu planen. Mehr akkulturierte Frauen weisen ein größeres Risiko auf, innerhalb der ersten 6 Monate nach der Geburt abzustillen, als weniger akkulturierte.

Schlussfolgerung Der Akkulturationsgrad hat relevante Bedeutung für einige Aspekte des Stillverhaltens bei Frauen mit Migrationshintergrund. Dies sollte sowohl bei Stillförderprogrammen als auch bei weiteren nationalen Stillstudien beachtet werden.

\section{Introduction}

The physiological nutritional advantages of breastmilk for the new-born, preventive aspects of breastfeeding for the baby's and mother's health as well as promotion of the emotional motherbaby bonding by breastfeeding are proven [1]. In national studies, factors promoting breastfeeding that act on one, two or all three dimensions of breastfeeding (intention to breastfeed, start and duration of breastfeeding) have identified, among other things, higher social status of the mother [2], a higher educational level of the mother [3], greater age of the mother [3], "married" marital status [4,5], competent care in the maternity clinic [6], positive earlier breastfeeding experience of the mother [6] and also the child's migration background [2]. Recent breastfeeding studies from other immigration countries [7-9] likewise emphasise the influence of a migration background on breastfeeding behaviour. A further influencing factor, though one not so far considered in German breastfeeding studies, might be the (changing) degree of acculturation of women with a migration background - otherwise, the reported advantageous breastfeeding behaviour of migrant women would be sustained. Acculturation describes the process of how persons with a migration background confront both the culture of their country of origin or of their parents' origin and the culture of the country of immigration. Sociocultural characteristics from the country of origin that are present in the immigrants can be reinforced in the second and third migrant generation or can experience modifications in the course of confrontation with social and cultural factors of the country of immigration and take on new forms. Acculturation takes place on both a group and an individual level. The concept of Berry et al. (1990) distinguishes four different results of an acculturation process, depending on whether the orientation is predominantly to the culture of origin and/or to the receiving culture, namely assimilation, integration, segregation and marginalisation [10]. Acculturation phenomena have intensively preoccupied epidemiological and also clinically oriented migration research in recent years, and this also included consideration of the acculturation aspects of breastfeeding behaviour. Examples include the studies by Rassin et al. (1994) and Gorman et al. (2007), who confirmed the "Latina paradox", a familiar phenomenon in migration research, for the breastfeeding rate in women of Hispanic origin in the US: the breastfeeding rate was highest in less acculturated women from Latin America, while women of Hispanic origin with a higher degree of acculturation showed the lowest breastfeeding rate [11, 12]. Something similar is described by Ahluwalia et al. (2012), who found that women who migrated from Latin American countries to the US show greater breastfeeding willingness and duration, compared with non-immigrant American women. Overall, a higher degree of acculturation appears to be negatively associated with the intention to breastfeed and breastfeeding duration [7].

Whether this phenomenon is also detectable for women in Germany with a migration background, has not been studied systematically to date. The study results presented below, which are based on data from a major prospective study sponsored by the German Research Foundation "Perinatal health and migration in Berlin” (2010-2013, project code DA 1199/2-1), should therefore answer the question of whether and how the degree of acculturation within a population of migrant women influences the start, time and duration of breastfeeding.

\section{Methods}

The data were obtained as part of the aforementioned study in three maternity clinics in Berlin (Charité - Campus Virchow-Klinikum Berlin-Wedding, Vivantes Klinikum am Urban, Berlin-Kreuzberg, Vivantes-Klinikum Berlin-Neukölln) with the aid of standardised face-to-face interviews.

\section{Inclusion/exclusion criteria}

In the one-year survey period from January 2011 to January 2012, all pregnant women who were admitted to one of the three par- 
ticipating maternity clinics in Berlin for the birth of their child and in whom the child was born with signs of life and after 24/0 weeks of pregnancy within the survey period in the respective clinic were invited to take part in the study. Other inclusion criteria were that the study participants were at least 18 years old when their child was born and were permanently resident in Germany. Under-age women, tourists not resident in Germany, women having termination of pregnancy and women with miscarriage and stillbirth were excluded.

\section{Survey time-points}

All women already surveyed before the birth (T1) on admission to the labour ward with a comprehensive questionnaire pack were surveyed again in the postnatal ward two or three days post partum with a second questionnaire (6 items) on the start of breastfeeding, the desired duration of breastfeeding and reasons for not breastfeeding (T2). At the third time-point (T3) 6 months post partum, only women who had been delivered between January and May 2011 in the Charité, Campus Virchow-Klinikum, were surveyed by means of phone interviews (subgroup). This focused on questions about the actual duration of breastfeeding, contraceptive behaviour post partum and availing of midwife services following delivery.

\section{Questionnaire set}

For classification of the migration background, the minimum set of indicators developed by Schenk et al. (2006) was chosen to record the migration status [13]. The "Frankfurt acculturation scale" questionnaire (FRAKK 15) [14] was used in addition for all women with a migration background. The questionnaire at the second survey time-point in the postnatal wards was available in eight other languages in addition to German (Arabic, English, French, Kurdish, Polish, Russian, Spanish, Turkish). The questionnaires for the phone interviews at the third survey time-point six months post partum were available in German, English, Turkish and Arabic as the project staff conducting the phone interviews spoke only these languages.

\section{Measurement of acculturation}

Knowledge of the language of the country of immigration is a frequently used proxy variable for the degree of acculturation in internationally published studies. Besides using the aforementioned Frankfurt acculturation scale (FRAKK 15), we performed a separate analysis, in which a very good and good knowledge of German stood for a higher degree of acculturation and knowledge of German that was not at least good stood for a low one. The duration of residence of first-generation migrants in the country of immigration is used internationally as a further proxy variable for the degree of acculturation. A brief duration of residence in the country of immigration is assigned a low degree of acculturation and longer residence is assigned a higher degree of acculturation. Different periods are proposed in the literature [15-17]. We distinguished four groups: residence for $0-4,5-9,10-14$, and 15 or more years [16].

\section{Statistics}

Plausibility tests were performed before statistical data analysis began. Drop-out analysis was performed. Data analysis was carried out with SAS statistics software, version 9.2, and with SPSS, versions 19, 20 and 22. Maternal age was divided into four age groups for analysis (18-24, 25-29, 30-34 and 35 or more years). For breastfeeding duration, two groups were distinguished: long breastfeeding duration ( $\geq 4$ months) and short breastfeeding duration (<4 months) [18]. To analyse the degree of acculturation using the Frankfurt acculturation scale (FRAKK 15), nine items on the scale were inverted and then added to a total score [14]. The higher the obtained score, the higher the degree of acculturation of the study participants. The range of possible scores is between 0 and 90 . The quartiles acted as cut off values to classify women with a migration background to a low ( $\leq 25$ th percentile), medium ( $>25$ th and $<75$ th percentile) and high degree of acculturation ( $\geq 75$ th percentile). To include questionnaires with one or two missing values, the mean of the available answers was obtained and used instead of the one or two missing values.

To determine group differences in the distribution of the outcomes start of breastfeeding, planned breastfeeding duration and actual breastfeeding duration, following univariate descriptive analysis, bivariate analysis was performed with stratification according to migration- or acculturation-related as well as sociodemographic and health-relevant influencing factors. The Pearson $\mathrm{X}^{2}$ test was used.

Breastfeeding behaviour was finally analysed using multivariate regression models. Other factors influencing the three main components, start/prevalence of breastfeeding, planned breastfeeding duration/intention to breastfeed and actual breastfeeding duration were then examined to determine whether any differences in overall breastfeeding behaviour can be attributed to migration- and/or acculturation-related factors or can be explained mainly by social and/or health-relevant factors. The following factors influencing breastfeeding behaviour were tested:

1. Sociodemographic factors: maternal age, desire to return to work, school education, monthly household net income.

2. Health behaviour: smoking in pregnancy.

3. Medical factors: manner of birth (section), premature birth, multiple birth.

4. Experience: breastfeeding experience, birth experience/parity.

5. Social support: permanent relationship, breastfeeding instruction in the clinic.

6. Migration/acculturation factors: migration status, degree of acculturation, country of birth or parents' country of origin (classified into Germany, Lebanon, Turkey, CIS states), residence duration, self-assessed knowledge of German, native language.

Cox regression was used to analyse the actual breastfeeding duration and possible influencing factors. A t-test for two independent samples was also used for comparison between the actual and planned breastfeeding duration in women who had already weaned at the third survey time-point six months post partum, on the assumption that many women initially plan longer breastfeeding periods. A p value of $<0.05$ was set as significance level for 
all data analyses and 95\% confidence intervals (Cl) were also stated.

\section{Ethics committee approval and data protection}

The study was approved by the ethics committee of Charité University Hospital Berlin, Campus Charité Mitte in February 2009 (EA1/235/08), including the data protection aspects.

\section{Results}

In the three Berlin maternity clinics taking part in the study, 8157 women were contacted in the study period for T1 interviews (before the birth). The overall T1 response rate was $89.6 \%$. Questionnaires from 7100 women were finally available for analysis. A total of 6884 women were contacted for the T2 interviews in the postnatal wards of the three Berlin maternity clinics. 90.4\% ( $n=6220)$ of these had started breastfeeding: $93 \%$ of second- and third-generation migrant women and $88.2 \%$ of non-migrants $(p<0.001)$. When considered according to country or region of birth, differences were also apparent: the breastfeeding prevalence was highest in women of Turkish origin at 96.2\% ( Table 1).

Of 747 women who had agreed to a phone survey six months after delivery (T3), 605 could be contacted (response $81 \%$ ). At this time, 312 (51.6\%) of the 605 women in this subgroup were still breastfeeding. Somewhat more than $40 \%(n=253)$ had already weaned, while $6.6 \%$ of this subgroup had never breastfed their babies $(n=40)$. The majority of the women who were still breastfeeding planned to continue to do so $(n=295)$.

\section{Start of breastfeeding}

Within the migrant population, the influence of the participants' degree of acculturation was examined to determine whether they start breastfeeding at all ("start of breastfeeding"). Apart from the results of the Frankfurt acculturation scale (FRAKK 15), the three proxy variables listed above were tested: the country of birth or origin, the self-assessed knowledge of German and the duration of residence in Germany, their country of immigration.

The degree of acculturation, measured with the FRAKK 15 acculturation scale, had no influence on the start of breastfeeding in either the non-adjusted or adjusted regression model ( $\vee$ Table 2 ).

The country or region of birth (see above) and the level of selfassessed knowledge of German showed no influence on the odds of starting breastfeeding within the migrant population (adjusted regression model). The duration of residence in Germany in years, corresponding to the aforementioned categories, did not show any significant influence on the odds of starting breastfeeding in the adjusted regression model.

\section{Planned breastfeeding duration}

The influence of the degree of acculturation, measured with FRAKK and the three proxy variables listed above, on the breastfeeding duration planned by the participants was examined using non-adjusted and adjusted regression models, in the same way as for the start of breastfeeding. In the adjusted model, a moderate and higher degree of acculturation reduced the odds of planning a long breastfeeding period ( $\vee$ Table 3 ).
- Table 1 Breastfeeding prevalence of study participants according to migration status, degree of acculturation and to country or region of birth: second (T2) and third (T3) survey time-point.

\begin{tabular}{|l|l|l|}
\hline & $\begin{array}{l}\text { Primary non- } \\
\text { breastfeeding } \\
(\text { T2) }\end{array}$ & \\
& $\mathbf{n}(\%)$ & \\
\hline All study participants & $664(9.6)$ & \\
\hline Migration status & $\begin{array}{l}\text { Breastfeeding } \\
\text { prevalence } \\
\text { postnatal (T2) }\end{array}$ & $\begin{array}{l}\text { Breastfeeding } \\
\text { prevalence } \\
6 \text { months pp (T3) } \\
\mathbf{n}(\%)\end{array}$ \\
\hline First-generation migrants & $2531(91.7)$ & $99(55.9)$ \\
\hline $\begin{array}{l}\text { Women with 2nd + 3rd genera- } \\
\text { tion migration background }\end{array}$ & $870(93.0)$ & $23(32.9)$ \\
\hline $\begin{array}{l}\text { Women with one immigrant } \\
\text { parent }\end{array}$ & $291(90.4)$ & $18(54.5)$ \\
\hline $\begin{array}{l}\text { Women without migration } \\
\text { background }\end{array}$ & $2528(88.2)$ & $172(52.9)$ \\
\hline Overall breastfeeding rate & $\begin{array}{l}6220(90.4) \\
(\mathrm{n}=6884 ; \\
\text { missing values }\end{array}$ & $312(51.6)$ \\
\hline & $\mathrm{n}=50)$ & \\
\hline
\end{tabular}

Degree of acculturation (women with 1st to 3rd generation migration background)

- low degree of acculturation (FRAKK 15)

- medium degree of \begin{tabular}{l|r|}
\hline $827(93.4)$ & $42(59.2)$
\end{tabular} acculturation (FRAKK 15)

- high degree of acculturation (FRAKK 15)

Country/region of birth (women with 1 st to 3 rd generation migration background)

\begin{tabular}{|l|r|r|}
\hline - Germany & $881(92.8)$ & $24(33.8)$ \\
\hline - Turkey & $660(96.2)$ & $28(54.9)$ \\
\hline - Lebanon & $348(94.3)$ & $7(43.8)$ \\
\hline - CIS states & $173(92.5)$ & $10(52.6)$ \\
\hline $\begin{array}{l}\text { Language knowledge (women } \\
\begin{array}{l}\text { with 1st to 3rd generation } \\
\text { migration background) }\end{array}\end{array}$ & & \\
\hline
\end{tabular}

\begin{tabular}{|l|r|r|}
\hline $\begin{array}{l}\text { - Native language German } \\
\text { and bilingual }\end{array}$ & $435(92.4)$ & $14(41.2)$ \\
\hline - Other native language & $2966(92.0)$ & $108(50.7)$ \\
\hline $\begin{array}{l}\text { - Very good - good } \\
\text { knowledge of German }\end{array}$ & $1564(92.8)$ & $66(48.2)$ \\
\hline $\begin{array}{l}\text { - Moderate to no knowledge } \\
\text { of German }\end{array}$ & $1448(91.1)$ & $44(57.1)$ \\
\hline $\begin{array}{l}\text { Residence (first-generation } \\
\text { immigrants) }\end{array}$ & & \\
\hline - 0-4 years & $884(91.9)$ & $29(67.4)$ \\
\hline - 5-9years & $523(91.9)$ & $27(62.8)$ \\
\hline - 10-14 years & $371(92.3)$ & $16(53.3)$ \\
\hline - 15+ years & $713(91.1)$ & $27(44.3)$ \\
\hline
\end{tabular}


- Table 2 Odds of breastfeeding according to degree of acculturation (FRAKK 15) in women with a 1st to 3rd generation migration background (non-adjusted and adjusted binary logistical regression analysis); $\mathrm{n}=2641$.

\begin{tabular}{|c|c|c|c|}
\hline & Odds ratios & $95 \% \mathrm{Cl}$ & p value \\
\hline \multicolumn{4}{|l|}{ Degree of acculturation (FRAKK 15) } \\
\hline - low degree of acculturation (FRAKK 15) & Reference & & \\
\hline - moderate degree of acculturation (FRAKK 15) & 0.94 & $0.65-1.35$ & 0.731 \\
\hline \multirow[t]{2}{*}{ - high degree of acculturation (FRAKK 15) } & 0.79 & $0.52-1.21$ & 0.279 \\
\hline & Adjusted odds ratios & $95 \% \mathrm{Cl}$ & p value \\
\hline \multicolumn{4}{|l|}{ Degree of acculturation (FRAKK 15) } \\
\hline - low degree of acculturation (FRAKK 15) & Reference & & \\
\hline - moderate degree of acculturation (FRAKK 15) & 0.99 & $0.66-1.49$ & 0.966 \\
\hline - high degree of acculturation (FRAKK 15) & 0.86 & $0.52-1.41$ & 0.540 \\
\hline \multicolumn{4}{|l|}{ Migration status } \\
\hline - First-generation migrants & Reference & & \\
\hline - Women with 2nd + 3rd generation migration background & 1.58 & $1.04-2.41$ & 0.031 \\
\hline \multicolumn{4}{|l|}{ Maternal age } \\
\hline - 18-24 years & Reference & & \\
\hline - 25-29 years & 1.01 & $0.61-1.68$ & 0.967 \\
\hline - 30-34 years & 0.77 & $0.46-1.31$ & 0.341 \\
\hline - $35+$ years & 0.60 & $0.35-1.04$ & 0.070 \\
\hline \multicolumn{4}{|l|}{ Net income } \\
\hline . >2600 Euro & Reference & & \\
\hline . >1500-2600 Euro & 1.28 & $0.71-2.32$ & 0.413 \\
\hline - 900-1500 Euro & 1.36 & $0.78-2.39$ & 0.279 \\
\hline - <900 Euro & 1.22 & $0.66-2.25$ & 0.529 \\
\hline \multicolumn{4}{|l|}{ School education } \\
\hline - Secondary school leaving examination & Reference & & \\
\hline - Technical/vocational school & 0.90 & $0.59-1.39$ & 0.633 \\
\hline - No educational qualification/primary school only & 0.74 & $0.43-1.30$ & 0.296 \\
\hline \multicolumn{4}{|l|}{ Birth mode } \\
\hline - Section (reference: no) & 0.33 & $0.26-0.48$ & $<0.0001$ \\
\hline - Multiple birth (reference: no) & 0.97 & $0.45-2.10$ & 0.942 \\
\hline - Breastfeeding experience (reference: no) & 10.54 & $6.28-17.68$ & $<0.0001$ \\
\hline - Breastfeeding instruction (reference: no) & 5.29 & $3.59-7.79$ & $<0.0001$ \\
\hline - Smoking during pregnancy (no) & Reference & & \\
\hline - Smoking during pregnancy: occasional/regular & 0.80 & $0.54-1.17$ & 0.246 \\
\hline \multicolumn{4}{|l|}{ Parity } \\
\hline - Nullipara & Reference & & \\
\hline - Primipara/bipara & 0.30 & $0.18-0.52$ & $<0.0001$ \\
\hline - Multipara & 0.24 & $0.12-0.49$ & $<0.0001$ \\
\hline \multicolumn{4}{|l|}{ Prematurity } \\
\hline - Premature birth (no) ( $\geq$ week 37 + 0) & Reference & & \\
\hline - Early premature birth ( $\geq$ week $34+0$ - < week $37+0$ ) & 0.42 & $0.25-0.70$ & 0.001 \\
\hline - Very early premature birth (< week 34 + 0) & 0.25 & $0.13-0.45$ & $<0.0001$ \\
\hline \multicolumn{4}{|l|}{ Partner } \\
\hline - Permanent relationship (reference: no) & 2.23 & $1.28-3.91$ & 0.005 \\
\hline
\end{tabular}


Knowledge of German and the duration of residence in Germany had no influence on the planned breastfeeding duration measured by the adjusted logistical regression model. For the factor country of birth, however, significant differences were apparent in the adjusted model for women born in Turkey; the odds for a planned long breastfeeding period were increased in this subgroup ( $\bullet$ Table 4 ).

\section{Frequency of early weaning}

Within the migrant population (women with first to third generation migration background), factors influencing early weaning were examined. In the adjusted Cox regression model, a higher degree of acculturation (according to FRAKK 15) and earlier school leaving were found to be predictors for the risk of weaning within the first six months post partum ( $\bullet$ Table 5).

No results could be submitted for the three proxy variables because the group sizes were too small.

\section{Discussion}

Although Germany has developed into an immigration society in recent decades, inclusion of migration and, in particular, acculturation aspects in health science studies is still not the rule. While the influence of acculturation on women's breastfeeding behaviour has already been addressed in international breastfeeding studies, though the results are inconsistent, and this may possibly be explained by the "healthy migrant effect" $[19,20]$ and the directly related "Latina paradox", especially in American studies [17, $21,22]$, conclusions in the German national context are still lacking.

Both migration-related and social influences for starting breastfeeding were found in our study. Unlike in international breastfeeding studies $[7,11,12]$, no acculturation-related differences at the start of breastfeeding, as measured with the FRAKK [14] and with the parameters language knowledge, duration or residence and country of birth, were shown in this Berlin study. Rather, previous breastfeeding experience, breastfeeding instruction in the clinic and in some cases a permanent relationship had a promoting effect on breastfeeding within the migrant population, while negative influences on breastfeeding included delivery by section, multiple birth and prematurity.

Acculturation-related influences were also found for the planned breastfeeding duration: using the acculturation scale (FRAKK 15) a "negative acculturation effect" [23] was found in that less acculturated migrants planned a longer breastfeeding period than more acculturated women. Similar results have been described in international breastfeeding studies [7, 8]. There were no differences in this regard in our population for the proxy variables of language knowledge and duration of residence.
Acculturation-related differences as regards the probability of weaning were also apparent: more acculturated women show a greater risk of weaning within the first six months post partum than less acculturated women with a migration background. Apart from earlier school leaving, a higher degree of acculturation (measured with the FRAKK 15) was shown to be a predictor for a greater probability of weaning. Similar results have been described in earlier international studies: Chapman and Pérez-Escamilla (2013) showed that different types of acculturation - "traditional", "assimilated", "less integrated" and "highly integrated" Hispanic women were distinguished - are associated with the probability of weaning, with a lower probability of weaning in the group of less integrated Hispanic women than "traditional", "assimilated" and "highly integrated" women from Latin America [9].

This study presents the first broad information on acculturation-related differences in breastfeeding duration for Germany.

\section{Strengths and Weaknesses of the Study}

\section{Strengths}

High response rate of just under $90 \%$; inclusion of migrant women independent of their language competence; relatively large sample.

\section{Weaknesses}

Limited representativeness - the study data might be applicable especially for conurbations with their specific migrant populations; recall bias when asking about breastfeeding times at the third survey time-point; no differentiation between "exclusive breastfeeding" versus "partial breastfeeding" - breastfeeding prevalence was recorded in the study using the parameter "any breastfeeding".

\section{Conclusion for Practice}

- Fox et al. (2017) generally advise against using proxy variables to measure acculturation aspects [24]. The results of the present study, however, show that the proxy variables "duration of residence" and "country of birth" can be used for certain limited questions.

- Migration- and acculturation-related aspects should be considered both in breastfeeding promotion programmes and in studies of breastfeeding behaviour.

- The inclusion of acculturation as a further social factor is a modern necessity in health research that is sensitive to diversity. 
- Table 3 Odds of a planned long breastfeeding duration ( $\geq 4$ months) according to degree of acculturation (FRAKK 15) in women with a 1st to 3rd generation migration background (non-adjusted and adjusted binary logistical regression analysis); n= 2152 .

\begin{tabular}{|c|c|c|c|}
\hline & Odds ratios & $95 \% \mathrm{Cl}$ & p value \\
\hline - low degree of acculturation (FRAKK 15) & Reference & & \\
\hline - moderate degree of acculturation (FRAKK 15) & 0.71 & $0.50-1.02$ & 0.067 \\
\hline \multirow[t]{2}{*}{ - high degree of acculturation (FRAKK 15) } & 0.71 & $0.47-1.09$ & 0.118 \\
\hline & Adjusted odds ratios & $95 \% \mathrm{Cl}$ & p value \\
\hline \multicolumn{4}{|l|}{ Degree of acculturation } \\
\hline - low degree of acculturation (FRAKK 15) & Reference & & \\
\hline - moderate degree of acculturation (FRAKK 15) & 0.61 & $0.41-0.89$ & 0.011 \\
\hline - high degree of acculturation (FRAKK 15) & 0.51 & $0.36-0.83$ & 0.007 \\
\hline \multicolumn{4}{|l|}{ Migration status } \\
\hline - First-generation migrants & Reference & & \\
\hline - Women with 2nd + 3rd generation migration background & 1.02 & $0.73-1.44$ & 0.891 \\
\hline \multicolumn{4}{|l|}{ Age } \\
\hline - 18-24 years & Reference & & \\
\hline - 25-29 years & 1.39 & $0.93-2.07$ & 0.104 \\
\hline - 30-34 years & 1.91 & $1.20-3.04$ & 0.007 \\
\hline - $35+$ years & 1.41 & $0.85-2.32$ & 0.182 \\
\hline \multicolumn{4}{|l|}{ Net income } \\
\hline - >2600 Euro & Reference & & \\
\hline . >1500-2600 Euro & 1.41 & $0.77-2.56$ & 0.262 \\
\hline . 900-1500 Euro & 0.98 & $0.56-1.70$ & 0.935 \\
\hline - $<900$ Euro & 0.74 & $0.41-1.35$ & 0.323 \\
\hline \multicolumn{4}{|l|}{ School education } \\
\hline - Secondary school leaving examination & Reference & & \\
\hline - Technical/vocational school & 0.71 & $0.47-1.07$ & 0.101 \\
\hline - No educational qualification/primary school only & 0.45 & $0.27-0.74$ & 0.002 \\
\hline \multicolumn{4}{|l|}{ Birth mode } \\
\hline - Section (reference: no) & 1.08 & $0.76-1.53$ & 0.672 \\
\hline \multicolumn{4}{|l|}{ (Return to) Work } \\
\hline - not planned & Reference & & \\
\hline - directly after maternity leave & 0.38 & $0.20-0.71$ & 0.003 \\
\hline - only after parental leave & 0.92 & $0.56-1.51$ & 0.752 \\
\hline " only later & 1.08 & $0.71-1.64$ & 0.712 \\
\hline - Breastfeeding experience (reference: no) & 1.32 & $0.67-2.60$ & 0.415 \\
\hline - Breastfeeding instruction (reference: no) & 0.87 & $0.62-1.21$ & 0.408 \\
\hline \multicolumn{4}{|l|}{ Smoking during pregnancy (no) } \\
\hline - Smoking during pregnancy: occasional/regular & 0.70 & $0.50-0.98$ & 0.039 \\
\hline \multicolumn{4}{|l|}{ Parity } \\
\hline - Nullipara & Reference & & \\
\hline - Primipara/bipara & 0.43 & $0.21-0.86$ & 0.018 \\
\hline - Multipara & 0.30 & $0.13-0.71$ & 0.006 \\
\hline \multicolumn{4}{|l|}{ Prematurity } \\
\hline - Premature birth (no) $(\geq$ week $37+0)$ & Reference & & \\
\hline - Early premature birth ( $\geq$ week $34+0-<$ week $37+0$ ) & 1.16 & $0.62-2.19$ & 0.638 \\
\hline - Very early premature birth (< week $34+0$ ) & 0.69 & $0.29-1.62$ & 0.391 \\
\hline \multicolumn{4}{|l|}{ Partner } \\
\hline - Permanent relationship (reference: no) & 0.93 & $0.48-1.78$ & 0.822 \\
\hline
\end{tabular}


- Table 4 Influence of the degree of acculturation (country/region of birth) on planned long breastfeeding duration ( $\geq 4$ months) in women with a first-generation migration background (non-adjusted and adjusted binary logistical regression analysis); $n=1470$.

\begin{tabular}{|c|c|c|c|}
\hline & Odds ratios & $95 \% \mathrm{Cl}$ & p value \\
\hline \multicolumn{4}{|l|}{ Country of birth } \\
\hline - Germany & Reference & & \\
\hline - Turkey & 3.01 & $1.72-5.28$ & $<0.0001$ \\
\hline - Lebanon & 0.53 & $0.34-0.82$ & 0.004 \\
\hline \multirow[t]{2}{*}{ - CIS states } & 1.48 & $0.72-3.06$ & 0.287 \\
\hline & Adjusted odds ratios & $95 \% \mathrm{Cl}$ & $p$ value \\
\hline \multicolumn{4}{|l|}{ Country of birth } \\
\hline - Germany & Reference & & \\
\hline - Turkey & 3.26 & $1.78-6.00$ & $<0.0001$ \\
\hline - Lebanon & 0.62 & $0.37-1.02$ & 0.058 \\
\hline - CIS states & 1.20 & $0.55-2.58$ & 0.649 \\
\hline \multicolumn{4}{|l|}{ Age } \\
\hline - 18-24 years & Reference & & \\
\hline - 25-29 years & 1.38 & $0.84-2.27$ & 0.202 \\
\hline - 30-34 years & 2.01 & $1.08-3.75$ & 0.028 \\
\hline - 35 years+ & 1.30 & $0.68-2.46$ & 0.427 \\
\hline \multicolumn{4}{|l|}{ Net income } \\
\hline . >2600 Euro & Reference & & \\
\hline . >1500-2600 Euro & 1.22 & $0.52-2.88$ & 0.646 \\
\hline - 900-1500 Euro & 0.89 & $0.40-1.98$ & 0.769 \\
\hline - <900 Euro & 0.73 & $0.31-1.72$ & 0.467 \\
\hline \multicolumn{4}{|l|}{ School education } \\
\hline - Secondary school leaving examination & Reference & & \\
\hline - Technical/vocational school & 0.663 & $0.36-1.22$ & 0.184 \\
\hline - No educational qualification/primary school only & 0.53 & $0.26-1.10$ & 0.090 \\
\hline \multicolumn{4}{|l|}{ Birth mode } \\
\hline " Section (reference: no) & 1.21 & $0.75-1.94$ & 0.433 \\
\hline - Breastfeeding experience (reference: no) & 1.19 & $0.50-2.83$ & 0.689 \\
\hline - Breastfeeding instruction (reference: no) & 1.02 & $0.67-1.56$ & 0.920 \\
\hline \multicolumn{4}{|l|}{ (Return to) Work } \\
\hline - not planned & Reference & & \\
\hline - directly after maternity leave & 0.45 & $0.17-1.17$ & 0.101 \\
\hline - only after parental leave & 0.67 & $0.36-1.25$ & 0.207 \\
\hline - only later & 1.09 & $0.66-1.79$ & 0.742 \\
\hline - Smoking during pregnancy (no) & Reference & & \\
\hline - Smoking during pregnancy: occasional/regular & 0.67 & $0.44-1.03$ & 0.070 \\
\hline \multicolumn{4}{|l|}{ Parity } \\
\hline - Nullipara & Reference & & \\
\hline - Primipara/bipara & 0.55 & $0.22-1.34$ & 0.187 \\
\hline - Multipara & 0.33 & $0.11-0.98$ & 0.045 \\
\hline \multicolumn{4}{|l|}{ Prematurity } \\
\hline - Premature birth (no) ( $\geq$ week 37 + 0) & Reference & & \\
\hline - Early premature birth ( $\geq$ week $34+0$ - < week $37+0)$ & 1.15 & $0.50-2.62$ & 0.742 \\
\hline - Very early premature birth (< week 34 + 0) & 0.50 & $0.17-1.42$ & 0.191 \\
\hline \multicolumn{4}{|l|}{ Partner } \\
\hline - Permanent relationship (reference: no) & 0.98 & $0.40-2.41$ & 0.961 \\
\hline
\end{tabular}


- Table 5 Risk of weaning within six months post partum; differentiated according to degree of acculturation (FRAKK 15) in women with a 1st to 3rd generation migration background (adjusted Cox regression analysis); $\mathrm{n}=216$.

\begin{tabular}{|l|l|l|l|}
\hline & Adjusted hazard ratios & $\mathbf{9 5 \%} \mathbf{C l}$ & P value \\
\hline Degree of acculturation & & \\
\hline - low degree of acculturation (FRAKK 15) & Reference & $1.01-2.96$ \\
\hline - moderate degree of acculturation (FRAKK 15) & 1.73 & $1.11-4.48$ \\
\hline - high degree of acculturation (FRAKK 15) & 2.23 & 0.047 \\
\hline School education & & \\
\hline - Secondary school leaving examination & Reference & \\
\hline - Technical/vocational school & 2.27 & $1.33-3.85$ \\
\hline - No educational qualification/primary school only & 2.71 & $1.19-6.17$ \\
\hline $\begin{array}{l}\text { Also adjusted for multiple birth, smoking in pregnancy, premature, delivery by section, parity, maternal age, breastfeeding experience, permanent rela- } \\
\text { tionship and net income }\end{array}$ & \\
\hline
\end{tabular}

\section{Conflict of Interest}

The authors declare that they have no conflict of interest.

\section{References}

[1] Koletzko B, Bauer CP, Cierpka $\mathrm{M}$ et al. Ernährung und Bewegung von Säuglingen und stillenden Frauen. Monatsschr Kinderheilkd 2016; 164 (S5): 433-457

[2] Lange C, Schenk L, Bergmann R. Verbreitung, Dauer und zeitlicher Trend des Stillens in Deutschland. Bundesgesundheitsbl 2007; 50: 624-633

[3] von der Lippe E, Brettschneider AK, Gutsche J et al. Einflussfaktoren auf Verbreitung und Dauer des Stillens in Deutschland. Ergebnisse der KiGGS-Studie - Erste Folgebefragung (KiGGS Welle 1). Bundesgesundheitsblatt, Gesundheitsforschung, Gesundheitsschutz 2014; 57: 849859

[4] Peters E, Wehkamp KH, Felberbaum RE et al. Breastfeeding duration is determined by only a few factors. Eur J Public Health 2005; 16: 162-167

[5] Rebhan B. Die prospektive Kohortenstudie „Stillverhalten in Bayern“: Analyse von Daten zur Kindergesundheit, zur Säuglingsernährung und zu Genussmittelkonsum und Rauchverhalten der Mütter [Dissertation]. München: Ludwigs-Maximilians-Universität zu München; 2008

[6] Rasenack R, Schneider C, Jahnz E et al. Factors associated with the duration of breastfeeding in the Freiburg birth collective, Germany (FreiStill). Geburtsh Frauenheilk 2012; 72: 64-69

[7] Ahluwalia IB, D’Angelo D, Morrow B et al. Association between acculturation and breastfeeding among Hispanic women: data from the Pregnancy Risk Assessment and Monitoring System. J Hum Lact 2012; 28 : 167-173

[8] Barcelona de Mendoza V, Harville E, Theall K et al. Acculturation and intention to breastfeed among a population of predominantly Puerto Rican women. Birth 2016; 43: 78-85

[9] Chapman DJ, Pérez-Escamilla R. Acculturative type is associated with breastfeeding duration among low-income Latinas. Matern Child Nutr 2013; 9: 188-198

[10] Berry JW. Psychology of Acculturation. Understanding Individuals moving between Cultures. In: Brislin R, ed. Applied Cross-Cultural Psychology. Thousand Oaks: SAGE Publications; 1990: 232-253
[11] Rassin DK, Markides KS, Baranowski T et al. Acculturation and the initiation of breastfeeding. J Clin Epidemiol 1994; 47: 739-746

[12] Gorman JR, Madlensky L, Jackson D] et al. Early postpartum breastfeeding and acculturation among Hispanic women. Birth 2007; 34: 308-315

[13] Schenk L, Bau AM, Borde T et al. Mindestindikatorensatz zur Erfassung des Migrationsstatus. Empfehlungen für die epidemiologische Praxis. Bundesgesundheitsblatt Gesundheitsforschung Gesundheitsschutz 2006; 49: 853-860

[14] Frankenberg E, Bongard S. Development and preliminary validation of the Frankfurt Acculturation Scale for Children (FRACC-C). International Journal of Intercultural Relations 2013; 37: 323-334. doi:10.1016/ j.ijintrel.2012.12.003

[15] Abraído-Lanza AF, Chao MT, Flórez KR. Do healthy behaviors decline with greater acculturation? Implications for the Latino mortality paradox. Soc Sci Med 2005; 61: 1243-1255

[16] Reiss K, Breckenkamp J, Borde T et al. Smoking during pregnancy among Turkish immigrants in Germany - are there associations with acculturation? Nicotine Tob Res 2015; 17: 643-652

[17] Sussner KM, Lindsay AC, Peterson KE. The influence of acculturation on breast-feeding initiation and duration in low-income women in the US. J Biosoc Sci 2008; 40: 673-696

[18] Kersting M, Dulon M. Fakten zum Stillen in Deutschland. Ergebnisse der SuSe-Studie. Monatsschr Kinderheilkd 2002; 150: 1196-1201

[19] Chen S, Binns CW, Zhao Y et al. Breastfeeding by Chinese mothers in Australia and China: the healthy migrant effect. J Hum Lact 2013; 29 : 246-252

[20] Nolan A, Layte R. The 'healthy immigrant effect'. Breastfeeding behaviour in Ireland. Eur J Public Health 2015; 25: 626-631

[21] Gibson-Davis CM, Brooks-Gunn J. Couples' immigration status and ethnicity as determinants of breastfeeding. Am J Public Health 2006; 96: 641-646

[22] McGlade MS, Saha S, Dahlstrom ME. The Latina paradox: an opportunity for restructuring prenatal care delivery. Am J Public Health 2004; 94: 2062-2065

[23] Ro A. The longer you stay, the worse your health? A critical review of the negative acculturation theory among Asian immigrants. Int J Environ Res Public Health 2014; 11: 8038-8057

[24] Fox M, Thayer Z, Wadhwa PS. Assessment of acculturation in minority health research. Soc Sci Med 2017; 176: 123-132 